\title{
Usage Patterns, Knowledge and Attitudes Regarding Dietary Supplement Intake Among Sri Lankan Elite Athletes: A Cross-Sectional Study
}

Suraweera Arachchilage Nimesha Rashani ( $\sim$ meshani1nisha@gmail.com )

Sri Lanka Anti-Doping Agency https://orcid.org/0000-0001-6129-6245

Punchividanelage Nilu Jayashika Fernando

Sri Lanka Anti Doping Agency

Shehani Pigera

Sri Lanka Anti-Doping Agency

Madunil Anuk Niriella

University of Kelaniya

Seevali Jayantha Jayawickreme

Sri Lankan Anti Doping Agency

Arjuna Priyadarsin De Silva

Sri Lanka Anti Doping Agency

Research article

Keywords: Dietary Supplement, Nutrition, Athletes, Sri Lanka, Doping, knowledge, Perception, Practice

Posted Date: June 19th, 2020

DOl: https://doi.org/10.21203/rs.3.rs-36080/v1

License: (9) (i) This work is licensed under a Creative Commons Attribution 4.0 International License.

Read Full License 


\section{Abstract}

Background: The use of dietary supplements without adequate knowledge regarding their constituents places professional athletes at great risk due to possibility of being positive in dope testing. The aim of this study was to identify the dietary supplements usage patterns among elite athletes in various sport types and investigate their knowledge and attitudes regarding that.

Methods: A cross-sectional study was conducted in which a self -administered anonymous questionnaire was used to collect data from 387 elite athletes participating in individual (athletics, karate, weightlifting, wrestling and shooting), team (cricket, volleyball, netball, rugby, football, kabaddi and hockey) and both (wushu and badminton) sports. The data were analysed using nonparametric tests; Pearson's chi square test with the level of significant of $p<0.05$.

Results: Out of 387 athletes, 354 (91.5\%) used dietary supplements, multivitamin (57\%), electrolyte (49.7\%), protein (43.5\%), calcium (19.7\%) and creatine (17.4\%) as the most prevalent types. Gender, social status, educational level, and professionalism had no impact with the supplement use whereas the type of sport played showed a significant impact on supplement intake $(p<0.05)$, with athletes in netball, rugby, wrestling, badminton and shooting showed $100 \%$ usage. Vitamin, protein and creatine usage were high among rugby, netball and weightlifting players $(p<0.05)$. The majority of athletes consume supplements to improve their performance (41.8\%) and energy (54.5\%). Further,60.5\% of the athletes claimed on self-prescription without medical advice. Two perceptions of, supplements are essential for maintain fitness and win awards were significantly high in males $(p<0.05)$. Athletes having participated in educational workshops and competed internationally showed significant concern about the contamination risk associated with supplements $(p<0.05)$. Rugby, weightlifting and netball players showed significant multiple supplement usage among others $(p<0.05)$.

Conclusion: This study confirms that dietary supplements are readily used by Sri Lankan elite athletes, while multivitamins, protein and energy drink products are preferred. Additionally, the majority of athletes engaged in supplement use with the aim of performance enhancement and increase energy. Nature of sport played was a determinant factor of net supplement usage while higher multiple supplement usage appeared among intensive sports.

\section{Background}

Scientific studies have found that elite athletes often use supplements as a strategy to achieve specific health benefits and this has been widespread during the past few decades [1,5]. United States (U.S.) food and drug administration defines dietary supplement under the Health and Education Act of 1994 (DSHEA) as a product used to supplement the diet and it is composed of one or more ingredient of vitamin, mineral, herb or botanical, amino acid and other substance or it can be a constituent, extract, metabolite, concentrate or combination of proceeding substances [2]. Among the dietary supplements protein, vitamin/multivitamin, minerals creatine, electrolyte, and energy drinks/sports drinks have commonly 
appeared among athletes $[19,27,30]$. However, despite the maturity in the sports field, overall athlete population has inclined to the supplements purposely to increase energy/ strength, stay healthy, immune recovery and performance enhancement $[17,20,22]$. Attitudes, knowledge on doping, and motivation have recognized as the indicators which affect the doping behaviour of athletes [ 8]. Doping behaviour highly noticed among male athletes rather than females where protein supplements and ergogenic acids were more preferred [19,34].

In addition to the overall body performance and physical appearance enhancement, supplements commonly account for recover nutrient impairments. Although it is a known fact that supplements can fulfill inadequate micronutrient content in the body, still supplements are not a better alternative for a healthy diet [36]. One example for the aforementioned fact is that the study conducted in Netherland found that equal micronutrient inadequacy has been shown between supplement users and non-users [37]. Therefore, rather than depending on supplements to fulfill the required nutrient content, athletes should concentrate on improving their regular dietary practices $[4,35]$.

Although many athletes supplement their diet with the various nutritional products, athlete's knowledge about real benefits and health implications of supplements is not at a satisfying level $[5,22]$. Such athletes might become positive in a doping test and ruin their sporting carriers. The composition and quality of supplements are still doubtful, due to insufficient standard regulations and laws behind them $[6,5]$. Therefore, consumer safety can't be fully guaranteed. However well- balanced diet and optimized training schedules ensure good performances during competing and training hours [21].

Not only the elite athletes but also armature athletes, university athletes and even school athletes are inclined to supplements worldwide $[9,11,12]$. This observation is also common among the Sri Lankan athlete population. According to media reports dope positive cases have given rise among Sri Lankan school boys and it is a gradually increasing treat [32].

There are varied motivating parties which possibly account for the doping behaviour of Sri Lankan athletes [4]. When considering the summary of the literature, nutritionists, physicians and coaches are the most frequent information sources about supplements $[1,10,16,19]$. Traders in the supplement industry trying to promote supplements to the athlete through social media, commercial advertisements and the internet. $[6,5,15]$ According to the past sales records, the global dietary supplement industry has generated 123.28 U.S. dollars in 2019 and it is projected to increase rapidly within the next few years. [7]. Due to the growing offer of dietary supplements, they are simply accessible to the sports community. However, the abundancy of these supplements among opponents, always pressurizes clean athletes during competitions thus, they have to win games fighting against dopers [22]. Further, the excessive consumption of dietary supplements may cause critical side effects and interactions within the body which affect the wellbeing of an athlete [21].

Consequently, to the previous research findings, the supplement prevalence rate among Sri Lankan national athletes has previously identified as $93.8 \%$ irrespective of their gender [4]. Among them, some athletes have used two or more dietary supplements simultaneously (multiple supplement usage). As 
reporting frequently their supplement usage also has influenced by doctors (45\%), team coaches (40\%), family, and friends (15\%) [4]. This study further observed that supplement consumption was significantly higher in athletes aged between 25 to 35 years than athletes under 18 years [4].

There are many supplements types in the local market of Sri Lanka, such as western supplements, herbal supplements and Ayurveda products which come from the traditional medical system. Almost all of these products are available as over the counter medicines in pharmacies and supermarkets thus, athletes can easily find them. [4]. Due to the poor knowledge and disregard of athletes, they may use them in any desire. However, there is a high possibility to be positive for dope test unintentionally. Such cases have more commonly appeared among the Sri Lankan athlete population. However, once after get positive for a dope test, the athlete should defend against legal inquiries by affirming their own fairness. Therefore, in another way inadvertent doping can down the mentality of athletes.

The dope positive cases in Sri Lanka, have highly observed among the type of sports such as rugby, weightlifting, cricket, boxing, athletics and etc. during past decades [31]. An unofficial site has reported about few doping cases, stating that Sri Lankan rugby and weightlifting players have punished several times against doping violations at international games during past years [32].

Therefore, by considering the aforesaid aspects and considering the emerging supplement usage in Sri Lanka, this study was conducted to identify the usage patterns, the status of knowledge and the practices concerning supplement use among Sri Lankan elite athletes.

\section{Method}

\section{Study design}

This was a cross-sectional approach involving 387 of professional Sri Lankan elite athletes from 14 types of sports including team sports (football, volleyball, rugby, netball, hockey, kabaddi, and cricket), individual sports (wrestling, shooting, athletics, weight lifting and karate) and mixed sports (wushu and badminton).

\section{Participants}

Three hundred and eighty-seven randomly selected elite athletes were participated for this study. 258 (66.8) \% male and 128 (33.2\%) female athletes aged between 18-41 years were there. The mean age of athletes participated was 26 years with a large number of athletes was in the range of 18 to 33 years of age. Approximately $63 \%$ of athletes were internationally exposed competitors.

\section{Analysis}

The independent variables were participants' demographic characteristics (age, sex, education level, district, marital state, gender, height and weight), type of sport played, the highest level of participation, duration of training. The dependent variables included were type of supplements, usage of supplements, 
motivational source, information source, intended benefit of the supplement, general practice and knowledge and attitudes about supplements use. Random sample recruitment was satisfied in the recruitment.

\section{Instruments}

A pre-tested self-administered questionnaire was used to gather data from the responders. The questionnaire was divided into 3 main parts. The first part included the athlete's socio-demographic characters such as gender, age, occupation and sports related characters such as type of sport, level of participation, duration of training. The second section consisted of questions regarding patterns of supplements used, intended purpose of use, information source and motivation to use. The latter part included about athletes' knowledge about supplements and prohibited substances in sports and personal beliefs or attitudes regarding supplement use. Similar tools have been used previously $[13,14,15]$.

\section{Procedure}

Briefly, after explaining the research and assuring the anonymity of the participants a written informed consent was collected by the researcher. Printed questionnaires were distributed among athletes according to their preferred language. Researcher delivered a detailed description of the study and helped to clarify any doubt that arose while answering the questionnaires. Participants were met at the sports federations, sports associations premise and at the training grounds. Data were exported to statistical software for analysis. Ethics approval for this study was obtained from the Ethics Review Committee, Faculty of Medicine, University of Kelaniya, Sri Lanka.

\section{Statistical analysis}

Statistical analysis was performed using Statistical Package for the Social Science(SPSS), version 22 software. Most of the variable in this study were categorical variables. few continuous variables such as age of the athlete were categorized into sub groups in the analysis. Chi-square test was used to compare two categorical variables and level of significance was considered as, $p$-value $<0.05$. After analysis most of the categorical data presented as percentages in bar charts and graphs.

\section{Results}

Approximately $97 \%$ response rate was approached and all the athletes consented to take part in this study. Few responders were rejected due to conflict with sample inclusion criteria. The total result was summarized under three category of supplements usage patterns, attitudes of athletes and knowledge about doping in sports and practices of athletes in order to give better explanation to the reader.

\section{A. Supplements usage patterns}

Net supplement usage was more than $91.5 \%$ among players who had competed above the district level. 
Table 1 Distribution of supplement usage with respect to sociodemographic characteristics, dietary characteristics and general practices.

\begin{tabular}{|c|c|c|}
\hline Character & $\begin{array}{l}\text { Total supplement } \\
\text { usage \% }\end{array}$ & $P$-value \\
\hline \multicolumn{3}{|c|}{ Socio-demographic characteristics } \\
\hline \multicolumn{3}{|l|}{ Gender } \\
\hline Male & 91.9 & 0.510 \\
\hline Female & 89.8 & \\
\hline Age categories & & 0.734 \\
\hline $18-25$ & 90.4 & \\
\hline $26-33$ & 92.6 & \\
\hline $34-41$ & 93.1 & \\
\hline \multicolumn{3}{|l|}{ Employed/Unemployed } \\
\hline Employed & 90.7 & 0.425 \\
\hline Unemployed & 93.8 & \\
\hline \multicolumn{3}{|l|}{ Marital status } \\
\hline Single & 90.6 & 0.611 \\
\hline Married & 92.1 & \\
\hline Education background & & 0.646 \\
\hline Below G.C.E. O/L & 100.0 & \\
\hline G.C.E.O/L & 90.2 & \\
\hline G.C.E.A/L & 91.1 & \\
\hline Graduate & 93.8 & \\
\hline Level of competition & & 0.927 \\
\hline International & 91.7 & \\
\hline National & 90.2 & \\
\hline Zonal & 90.9 & \\
\hline Provincial & 94.4 & \\
\hline Province of living & & 0.279 \\
\hline Western & 94.2 & \\
\hline
\end{tabular}




\begin{tabular}{|l|c|}
\hline North central & 86.4 \\
\hline North western & 85.4 \\
\hline Central & 93.4 \\
\hline Uva & 77.8 \\
\hline Sabaragamuwa & 90.6 \\
\hline Southern & 91.2 \\
\hline General practices & \\
\hline Participation for anti-doping educational & \\
\hline workshops & 94.9 \\
\hline Yes & 90.1 \\
\hline No & \\
\hline Whether checking the label of medicine & \\
\hline Yes & 76.2 \\
\hline No & 90.5 \\
\hline Dietary Characteristics & \\
\hline Vegetarian & 85.7 \\
\hline Non vegetarian & 91.6 \\
\hline
\end{tabular}

Total supplement usage of athletes was assessed against socio-demographic characteristics, dietary habits and practices of athletes with the aim of identifying any existing pattern with athletes' characteristics. As shown in Table 1, Supplement usage has not significantly associate with gender, age, marital state, professionalism, education state, dietary habits and province of living. The highest and least supplement usage were shown in the Western and Uva province respectively, while all provinces have apprehended more than $75 \%$ of supplement use. Supplement usage did not seem affected by athletes' dietary habits and general practices significantly.

The highest supplement usage was among athletes in cricket, wrestling, badminton, rugby, netball, shooting, wushu, kabaddi weightlifting and volleyball compared to the studied sports. According to the statistics it was strongly evident that the nature of sport played has significantly associated with supplement usage $(p<0.05)$. Players in netball, wrestling, badminton and shooting (supplement use $=$ $100 \%$ ) showed significant increase in supplement use than athletics, football and karate players (supplement use $<85 \%, p<0.05$ ). Further, rugby, volleyball, weightlifting and cricket (supplement use 
$>93 \%$ and $<100 \%$ ) players showed significant increase in supplement use than karate players (supplement use $=75 \%, \mathrm{p}<0.05$ ).

Players with highest supplement intake has medium level education status. Thus, most of them have completed their secondary education. All together vitamin, protein and creatine supplements usage (multiple supplement) was significantly higher among athletes who played netball (82.4\%), rugby (72.7\%) and weightlifting $(76.5 \%)$ games than others $(p<0.05)$. The highest Creatine supplement use appeared among athletes played Wrestling (73.7\%).

Prevalence of different supplements used by athletes is shown in figure 2 .

As shown in fig. 2 multivitamin (57\%), electrolyte replacement drinks (49.7\%) and protein supplements (43.5\%) are the most commonly used supplements among athletes in the current study. The most prevalent supplement usage pattern was three products per day $(56.8 \%)$ which is composed of vitamin, protein and creatine.

Different sources influenced on supplementation of athletes were given in figure 3 .

As indicated by the study it showed that a majority of athletes has taken supplements depending on their own (60.5\%). A substantial number of them appeared due to influenced by coaches $(24.7 \%)$ and doctors (28.7\%) while remaining showed very low influence on supplement use.

Further, food consumption patterns of the players and their relativity with supplement use investigated in this study.

As discovered by the results, the highest quote of athletes consumed a daily carbohydrate-rich diet (80\%).Additionally, vegetables and meat-rich diet and junk foods had daily usage of $4.2 \%$ and

$10.9 \%$ respectively. $13.8 \%$ of athletes used a cereal rich diet for breakfast and $0.3 \%$ used cereals for dinner. $85.7 \%$ net supplement use could be observed among vegetarian athletes (3.6\%). Moreover,81.9\% of the athletes consumed fruits, $(54.9 \%)$ porridge, $(43.0 \%)$ soup and $(22.8 \%)$ herbal drinks made of medicinal plants. They also showed a similar tendency to use supplements. (more than $90 \%$ ).

\section{B. Attitudes of athletes}

As shown in fig.4, within the encountered population, a majority of athletes used supplements to stronger the body with the target of maximum performance. while a few numbers of athletes used supplements to intake nutrition which were not absorbed due to poor dietary habits. 
Table 2 Variation of athlete perception with gender.

\begin{tabular}{|lll|}
\hline perception & Male (\%) & Female (\%) \\
\hline supplements are essential to keep up fitness & 94.0 & 84.9 \\
\hline Supplements were essential for award-wining & 76.6 & 66.7 \\
\hline *p value $<0.05$ & & \\
\hline
\end{tabular}

Both of above mentioned perceptions were significantly strong among male athletes than female athletes $(p<0.05)$. Among the athletes with the attitude of supplements are essential to maintain fitness $21.7 \%$ of players reported their participation in anti-doping workshops and $91.6 \%$ of athletes were aware of prohibited substances in sports.

\section{Knowledge about doping in sports and practices of athletes.}

Table 3 Comparison of knowledge about anti - doping among athletes

\begin{tabular}{|lll|}
\hline Factor & $\begin{array}{l}\text { Have adequate Knowledge } \\
\text { about anti- } \\
\text { doping (\% athletes) }\end{array}$ & $\begin{array}{l}\text { Don't have adequate Knowledge } \\
\text { about anti- } \\
\text { doping (\% athletes) }\end{array}$ \\
\hline Supplement usage & 91.3 & 87.5 \\
\hline $\begin{array}{l}\text { Competed in } \\
\text { International } \\
\text { level }\end{array}$ & 97.9 & 2.1 \\
\hline $\begin{array}{l}\text { Competed in National } \\
\text { level or } \\
\text { below }\end{array}$ & 92.2 & 7.8 \\
\hline
\end{tabular}

The results showed that irrespective to the knowledge about anti-doping athletes still engaged in supplement use. Further, anti-doping knowledge among athletes was assessed by considering the level of exposure to competition. The results have disclosed that athlete knowledge about doping in sports did not vary with the level of exposure to competition.

Furthermore, participation in anti-doping educational workshops have significantly improved the practice of inform about banned substances in sports to the physician when go for treatments $(p<0.05)$. The education level was not a determinant factor of acquired doping knowledge among athletes in this study. Even though athletes influenced by other sources (98.2\%) to take supplements showed significantly higher knowledge about doping in sports than self -influenced athletes $(94.0 \%, p<0.05)$. 
When it comes to purchasing supplements, $76.2 \%$ of athletes checked for the label before actual buying. Among them, athletes who had participated in anti-doping educational workshops (86.7\%) were significantly more likely to check the label of supplements than non-participants $(74.6 \%),(P=0.05)$. Furthermore, internationally exposed athletes showed a significant practice of checking label before actual purchasing $(80.9 \%)$ than national level athletes $(68.3 \%),(p<0.05)$.

The data showed that, among the supplement users, creatine (37.3\%), vitamin (51.8\%) and protein $(14.8 \%)$ users showed significant unawareness about the supplements type they consumed $(p=0.05)$.

\section{Discussion}

High supplement usage was detected among Sri Lankan elite athletes where $91.5 \%$ of elite athletes reported to use at least one supplement. The proportion of supplement users among Sri Lankan professional athletes remain almost similar to 2006 (93.8\%) and 2018 (91.5\%), maybe because athletes were very concerned about rehydrating themselves after training and the Institute of Sports Medicine in Sri Lanka supplied multivitamins and minerals to the athletes at no cost as a benefit of the free health care system in the country.

Furthermore, the current prevalence rate is comparatively similar with past recorded values in developed counties $[16,17]$ and comparatively higher with what has been recorded in some other Asian countries $[18,19,20]$. Although supplement usage may depend on socio- demographic factors such as gender and age category, the current study was not complied with that. Similar observations have reported in the literature $[4,22,19]$. Socio-economic characteristics such as education background and professionalism did not show any significant agreement with the supplement use of athletes. Diversely, some studies discussed that having educated well or engaged in well-paying jobs were determinant factors of supplement use where athletes with high education and well-paying jobs tend to use more supplements than their underprivileged counterparts [22,25]. Further, characteristics such as level of competition exposed and the geographical distribution did not show any significant impact on the supplement use.

On the contrary, earlier study reported that, highly elite athletes engaged in more supplement use than noelite athletes. $[23,26]$. Other considered practices such as having participated for anti-doping educational workshops, checking labels of supplements and food habits did not show any significant pattern of supplement use. Unlike this research findings, a study conducted in U.S. has proven by the results that participation in educational programs have productively reduced the use of supplements [33].

The multiple supplement usage prominently appeared among National level athletes in Sri Lanka.This observation compared to the earlier study findings conducted in Sri Lanka where $29 \%$ consumed four products /day and 10\% consumed six products/day in 2006 [4]. In present study the most prevalent multiple supplement usage pattern was three products/day (56.8\%) which consisted of vitamin, protein and creatine. 
A high prevalence of herbal supplements was expected during the current study due to higher abundance and popularity of them as health safe products among Sri Lankans. However, herbal supplement usage gave rise from the present study findings (13.5\%) was very low than the predicted prevalence by the researchers. This observation collaborates with the previous findings $[4,27,28,22]$. It shows that the although indigenous medicine system in Sri Lanka has introduced lot of herbal supplements to the local market, athletes less perceived need of them. On the other hand, this discrepancy may be due to wide availability, easy administration and instant results of Western dietary supplements.

The vast majority of players consuming supplements appeared within rugby, wrestling, badminton, netball and shooting players and minority was within karate players. Nevertheless, a study conducted in Greece has proven that individual sports players depended more on supplements other than team players [26]. Such a coherent observation was not disclosed by the current study results. That may be due to the reason of evaluation tools adopted to assess supplements intake in the current study were not strong enough. The consumption of supplements in various sports has shown some changes over the past years compared to the study conducted in Sri Lanka in 2006. Elite athletes in karate showed a decrease in supplements usage in 2018 (75\% in 2018 and $100 \%$ in 2006 ) while football showed increase $(70.6 \%$ in 2006 and $84 \%$ in 2018) and badminton remain unchanged (100\% in 2006 and 2018) [4]. This emphasizes the need of conducting anti-doping education programs sports wise.

Multivitamin (57\%) and rehydration drinks (49.7\%) and protein supplements (43.5\%) observed as the most preferred supplement types among the population accessed. Similar prevalence has reported previously among the athletes in Malaysia [19]. Additionally, multivitamin and sports drinks have been again reported as the most frequently used supplements in the studies conducted in Sri Lanka and German $[4,16]$. Contradictorily to the present findings, Sports drink has reported as the most used supplement in the studies conducted in Saudi Arabia and Singapore while multivitamin has shown a middle usage $[13,18]$.

Altogether the use of vitamin, protein and creatine supplements highly appeared among the players in which team of rugby, netball and weightlifting and the highest creatine usage appeared among wrestling players. This may be due to the reason of fitness requirements such as muscular strength, good endurance, anaerobic demand and other related factors such as the risk of injury and in-depth training schedules accompanied by those sports [19]. Same as the consequent of the present study, past studies have explored that athletes who followed intensive training were more likely to consume creatine and protein supplements and in other words, overall higher supplement usage appeared among the endurance athletes $[5,17]$.

However, multiple supplement usage may result harmful side effects due to the possible intermolecular interactions among nutrients within the human body such as inhibition of some nutrient adsorption from consumed foods [4,23]. Supplements are not routinely recommended for any person unless they are risk of having poor food choices, malabsorption of micronutrients due to abnormal metabolism, following weight reducing diets or taking imbalanced nutrition due to life-style related behaviour [29]. The 
recommendation is that supplements should always be taken under the advice of an accredited physician or nutritionist [27].

Furthermore, $60.5 \%$ of athletes have declared that they decided the certain supplement use on their own. The percentage of players who have been influenced by the media and internet was comparatively low. This is consisted of the earlier findings where less than $10 \%$ of athletes referred supplements from the online resources and the physician and coaches were the most preferred information sources [13]. The reason for less influenced by the internet may have resulted due to athletes' poor knowledge about modern technology and less accessibility.

Athletes' day to day dietary habits were taken into consideration in this study. As per the records, $80 \%$ of athletes claimed on taking daily a carbohydrate-rich diet. The percentages of athletes who consume health foods and balanced diet for their main meals were very low. It affirmed that athletes have underscored the value of healthy foods and instead of that they highly depend on supplements.

Most athletes have inclined to supplement use with the intention of gaining energy /strength and enhance performance. On the contrary, German study has reported that major motivational perceptions were related to maintain heath whereas performance enhancement was less frequently observed [16]. Meanwhile a study conducted in Korea reported, gender based reason to use supplements while purposely male athletes used for energy enhancement and female athletes used for well-being, energy enhancement and recoverability [20]. The use of Supplements to enhance performance has shown a reduction from 2006 (79\%) to 2018 (41.8\%) among Sri Lankan athletes [4]. This may be due to the establishment of Sri Lanka Anti-Doping Agency(SLADA) in 2013 and initiate educating the athletes about the risk associated with performance enhancing substances.

However, according to the reported literature, athlete performances have not merely increased due to supplements consumption while only a few have given the positive outcome [28]. Furthermore, many athletes used supplements without having an idea about their real benefits. This dominantly observed among the athletes who consumed vitamin and creatine supplements. It indicated that certain supplement use should undergo proper evaluation before use.

Most of the male athletes believed that "supplements are essential to win and maintain physical fitness" rather than good training and practices. This emphasized that male athletes have been misled by their personal beliefs. Similar observations have previously recognized in the literature highlighting that male athletes hold better "supplement-doping attitudes" than females [19] and male athletes were more inclined to doping than females [34].

Consequently, educational workshops conducted by SLADA have been shown to significantly increase the athletes' practice of inform about prohibited substances in sports to the physician during medication. Moreover, practice of checking label of supplements against dope positive substances has significantly increased among the players who have been exposed internationally and participated in anti -doping educational workshops. This indicated that higher the experience, talent and knowledge, there is less 
probability to have unintentional doping. Further,a novel finding in this study is that participation in educational workshops has increased the safety practices of athletes against unintentional doping.

Based on the current study data, knowledge about anti-doping did show any significant association with the level of education. With the exception of that tertiary educated Malaysian national athletes have claimed about higher knowledge of doping than lowers [19].

However, athletes' enthusiasm should be further developed through awareness programs, explaining the role of sports doctors and nutritionists within the field of doping in sports. On the other hand, the app developed by SLADA very recently to find the status of any medicine against prohibition should be brought to the notice of whole sports community. So that it would lower the percentage of inadvertent doping cases.

Finally, this study had some limitations that should be discussed to improve the true results. Although the anonymous questionnaire was tested, some athletes try to purposely hide the true situation of their supplement use. Also due to lack of proper identification of the supplements they consume, athletes showed difficulty to categorize supplements accurately. Further, issues such as differences in understanding the questions and lack of personalized questions were noticed in this study.

Despite the above mentioned limitations, authors believed that current scenario of dietary supplement usage patterns, knowledge about banned substances and doping in sports and general perceptions and practices of Sri Lankan athletes have been analysed through this study and these finding would be more valuable to the scientific community to get an idea about the prevalence of supplement use within Sri Lankan elite athletes.

\section{Conclusion}

In conclusion, there is a widespread use of dietary supplements among Sri Lankan elite athletes where vitamin-mineral, protein and energy drink products were the most prevalent. Male athletes believed more than female athletes that supplements were essential to win and maintain good health. Sri Lankan athletes consume supplements irrespective of the socio-demographic factors including gender, age, professionalism, social status, education and level of competition participated.

Athletes representing both individual and team sports showed equal prevalence in supplements and most of them taking supplements with the purpose of improving performance, energy and strength. Higher vitamin, protein and creatine (multiple supplement) consumption appeared among the players involved in endurance and intensive sports while the overall lowest supplement use was among those engaged in karate.

Since the supplement prevalence rate among Sri Lankan athletes has not considerably changed throughout the past decade, the current anti-doping educational programs should be further evaluated 
and improved effectively with the aim of changing athlete's attitudes regarding supplements and discouraging the use of them.

\section{List Of Abbreviations}

DSHEA: Dietary Supplement Heath and Education Act

SPSS: Statistical Software for Social Science

SLADA: Sri Lanka Anti-Doping Agency.

U.S.: United States

U.K.: United Kingdom

G.C.E. O/L: General certificate examination of Ordinary level

G.C.E. A/L: General certificate examination of Advanced Level

\section{Declarations}

\section{Ethics approval and consent to participate}

This study was conducted, complying with the declaration of Dr. Seevali Jayawicreme, Director General of Sri Lanka Anti-Doping Agency and ethics approval to conduct this study was obtained by the Ethics Review Committee of Faculty of Medicine, University of Kelaniya. In written consent to participate with this study was obtained from all athletes.

\section{Consent for publication}

Not Applicable

\section{Availability of data and materials}

The data set generated or analysed during the current study are available with the corresponding author on reasonable request and most of the data analysed during the study has published in this article.

\section{Competing interest}

All authors declare that they have no competing interests. 


\section{Authors contribution}

SANR contributed to the study conceptualization, data collection, data analysis and manuscript writing.PNF contributed to the study conceptualization, data collection, data analysis and manuscript revision. SP contributed to the study conceptualization, data collection, data analysis and manuscript revision. MAN contributed to the study conceptualization. SJJ and APDS contributed to the study conceptualization and manuscript revision. All authors read and approved the final manuscript.

\section{Funding}

There was no any funding to the research. The budget of the study was covered by the national budget allocation to the Sri Lanka Anti-Doping Agency.

\section{Acknowledgment}

We thank for Ministry of Sports, Sri Lanka, all national sports federations and national sport team coaches for their help to getting touch with athletes with their busy time schedules and all the athletes who were consented to participate in this research study.

\section{References}

1. Erdman KA, Fung TS, Doyle-Baker PK, Verhoef MJ, Reimer RA. Dietary supplementation of highperformance Canadian athletes by age and gender. Clin J Sport Med. 2007;17(6):458-464; doi:10.1097/JSM.0b013e31815aed33

2. U.S. Food and Drug Administration; Dietary Supplement products ingredients \&. http://www.fda.gov/food/dietary-supplements/dietary-supplement-products-ingredients (2020) .Accessed 29 Jan 2020.

3. Maughan RJ, Greenhaff PL, Hespel P. Dietary supplements for athletes: emerging trends and recurring themes. J Sports Sci. 2011;29 Suppl 1: S57-S66; doi:10.1080/02640414.2011.587446

4. de Silva A, Samarasinghe Y, Senanayake D, Lanerolle P. Dietary supplement intake in national- level Sri Lankan athletes. Int J Sport Nutr Exerc Metab. 2010;20(1):15-20; doi:10.1123/ijsnem.20.1.15

5. Baltazar-Martins G, Brito de Souza D, Aguilar-Navarro M, Muñoz-Guerra J, Plata MDM, Del Coso J. Prevalence and patterns of dietary supplement use in elite Spanish athletes. J Int Soc Sports Nutr. 2019;16(1):30. doi:10.1186/s12970-019-0296-5

6. Molinero 0 , Márquez S. Use of nutritional supplements in sports: risks, knowledge, and behavioralrelated factors. Nutr Hosp. 2009;24(2):128-134.

7. https://www.grandviewresearch.com/industry-analysis/dietary-supplements market. Accessed 27 March 2020. 
8. Morente-Sánchez J, Zabala M. Doping in sport: a review of elite athletes' attitudes, beliefs, and knowledge. Sports Med. 2013;43(6):395-411; doi:10.1007/s40279-013-0037-x

9. Nieper A. Nutritional supplement practices in UK junior national track and field athletes. Br J Sports Med. 2005;39(9):645-649; doi:10.1136/bjsm.2004.015842

10. Erdman KA, Fung TS, Reimer RA. Influence of performance level on dietary supplementation In elite Canadian athletes. Med Sci Sports Exerc. 2006;38(2):349-356; doi: 10.1249/01.mss.000018 7332. 92169.e0

11. Sobal J, Marquart LF. Vitamin/mineral supplement use among high school athletes. Adolescence. 1994;29(116):835-843.

12. Tian $\mathrm{HH}$, Ong WS, Tan CL. Nutritional supplement use among university athletes in Singapore. Singapore Med J. 2009;50(2):165-172.

13. Aljaloud SO, Ibrahim SA. Use of Dietary Supplements among Professional Athletes in Saudi Arabia. J Nutr Metab. 2013; 2013:245349; doi:10.1155/2013/245349

14. Bianco A, Mammina C, Paoli A, et al. Protein supplementation in strength and conditioning adepts: knowledge, dietary behavior and practice in Palermo, Italy. J Int Soc Sports Nutr.2011;8(1):25. Published 2011;29; doi:10.1186/1550-2783-8-25

15. Mooney R, Simonato P, Ruparelia R, Roman-Urrestarazu A, Martinotti G, Corazza O. The use of supplements and performance and image enhancing drugs in fitness settings: A exploratory cro sssectional investigation in the United Kingdom. Hum Psychopharmacol.2017;32(3):10.1002/ up.2 619; doi:10.1002/hup.2619

16. Braun H, Koehler K, Geyer H, Kleiner J, Mester J, Schanzer W. Dietary supplement use among elite young German athletes. Int J Sport Nutr Exerc Metab. 2009;19(1):97-109;

doi:10.1123/ijsnem.19.1.97

17. Wiens K, Erdman KA, Stadnyk M, Parnell JA. Dietary supplement usage, motivation, and education in young, Canadian athletes. Int J Sport Nutr Exerc Metab. 2014;24(6):613-622; doi:10.1123/ijsnem.2013-0087

18. Slater G, Tan B, Teh KC. Dietary supplementation practices of Singaporean athletes. Int J Sport Nutr Exerc Metab. 2003;13(3):320-332; doi:10.1123/ijsnem.13.3.320

19. Balaravi B, Chin MQ, Karppaya H, Chai WJ, Quah LW, Ramadas A. Knowledge and Attitude Related to Nutritional Supplements and Risk of Doping among National Elite Athletes in Malaysia. Malaysian Journal of Nutrition. 2017;23(3).

20. Kim J, Lee N, Kim EJ, Ki SK, Yoon J, Lee MS. Anti-doping education and dietary supplementation practice in Korean elite university athletes. Nutr Res Pract. 2011;5(4):349-356; doi:10.4162/nrp.2011.5.4.349

21. Omeragić E, Đeđibegović J, Sober M, Marjanović A, Dedić M, Niksić H, Fidahić M. Use of dietary supplements among elite athletes. SportLogia. 2015;11(1).

22. Muwonge $H$, Zavuga R, Kabenge PA, Makubuya T. Nutritional supplement practices of professional Ugandan athletes: a cross-sectional study. Journal of the International Society of Sports Nutrition. 
2017;14(1):41.

23. Knapik JJ, Steelman RA, Hoedebecke SS, Austin KG, Farina EK, Lieberman HR. Prevalence of Dietary Supplement Use by Athletes: Systematic Review and Meta-Analysis. Sports Med. 2016;46(1):103123; doi:10.1007/s40279-015-0387-7

24. Knapik JJ, Trone DW, Austin KG, Steelman RA, Farina EK, Lieberman HR. Prevalence, Adverse Events, and Factors Associated with Dietary Supplement and Nutritional Supplement Use by US Navy and Marine Corps Personnel. J Acad Nutr Diet. 2016;116(9):1423-1442; doi: 10.1016/j.jand.2016.02.015

25. Lacerda FM, Carvalho WR, Hortegal EV, Cabral NA, Veloso HJ. Factors associated with dietary supplement use by people who exercise at gyms. Rev Saude Publica. 2015; 49:63; doi:10.1590/S0034-8910.2015049005912

26. Giannopoulou I, Noutsos K, Apostolidis N, Bayios I, Nassis GP. Performance level affects the dietary supplement intake of both individual and team sports athletes. J Sports Sci Med. 2013;12(1):190196. Published 2013 Mar 1.

27. Maughan RJ, Depiesse F, Geyer H; International Association of Athletics Federations. The use of dietary supplements by athletes [published correction appears in J Sports Sci. 2009 Apr;27(6):667]. J Sports Sci. 2007;25 Suppl 1: S103-S113; doi:10.1080/02640410701607395

28. Sousa M, Fernandes MJ, Carvalho P, Soares J, Moreira P, Teixeira VH. Nutritional supplements use in high-performance athletes is related with lower nutritional inadequacy from food. J Sport Health Sci. 2016;5(3):368-374; doi: 10.1016/j.jshs.2015.01.006

29. Huskisson E, Maggini S, Ruf M. The role of vitamins and minerals in energy metabolism and wellbeing. J Int Med Res. 2007;35(3):277-289; doi:10.1177/147323000703500301

30. Aljaloud SO, Ibrahim SA. Use of Dietary Supplements among Professional Athletes in Saudi Arabia. J Nutr Metab. 2013; 2013:245349; doi:10.1155/2013/245349

31. Madushani A.A.L. "Let's preserve the spirit of sport": Preventive approaches of using performance enhancing drugs among national level athletes in Sri Lanka. http://sites.les.univr.it/eisic/wpcontent/uploads/2018/07/20-EISIC-Madhushani.pdf (2020).Accessed 28 March 2020.

32. Colombage D. (2020). Drug galore in Sri Lankan Sports. The Sunday Leader. 2020.http://www.thesundayleader.Ik/2011/06/12/drugs-galore-in-sri-lanka-sport/.Accessed 28 March 2020.

33. DesJardins M. Supplement use in the adolescent athlete. Curr Sports Med Rep. 2002;1(6):369- 373. doi:10.1249/00149619-200212000-00011

34. Sas-Nowosielski K, Swiatkowska L. Goal orientations and attitudes toward doping. Int J Sports Med. 2008;29(7):607-612. doi:10.1055/s-2007-965817

35. Van Thuyne W, Van Eenoo P, Delbeke FT. Nutritional supplements: prevalence of use and contamination with doping agents. Nutr Res Rev. 2006;19(1):147-158. doi:10.1079/NRR2006122

36. Larson-Meyer DE, Woolf K, Burke L. Assessment of nutrient status in athletes and the need for supplementation. International journal of sport nutrition and exercise metabolism. 2018 Mar $1 ; 28(2): 139-58$.

Page $17 / 19$ 
37. Wardenaar F, Brinkmans N, Ceelen I, Van Rooij B, Mensink M, Witkamp R, De Vries J. Micronutrient intakes in 553 Dutch elite and sub-elite athletes: Prevalence of low and high intakes in users and non-users of nutritional supplements. Nutrients. 2017 Feb;9(2):142.

\section{Figures}

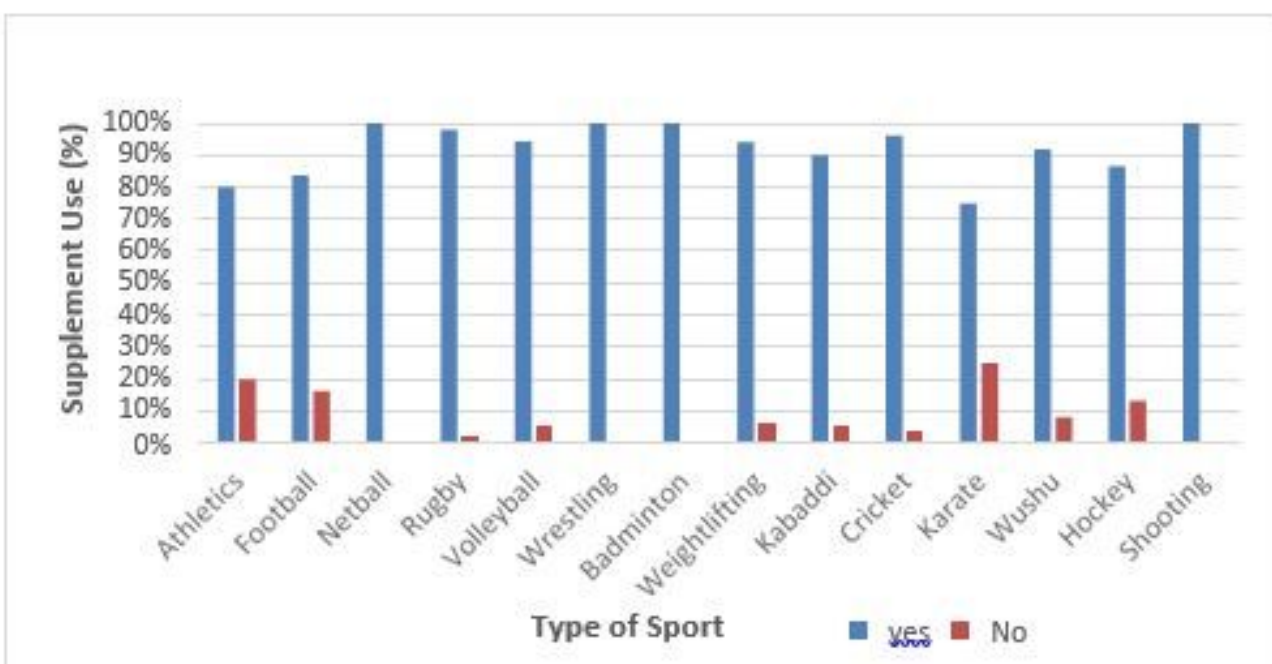

Fig. 1 - Distribution of supplement use among different sports types.

\section{Figure 1}

Figure 1

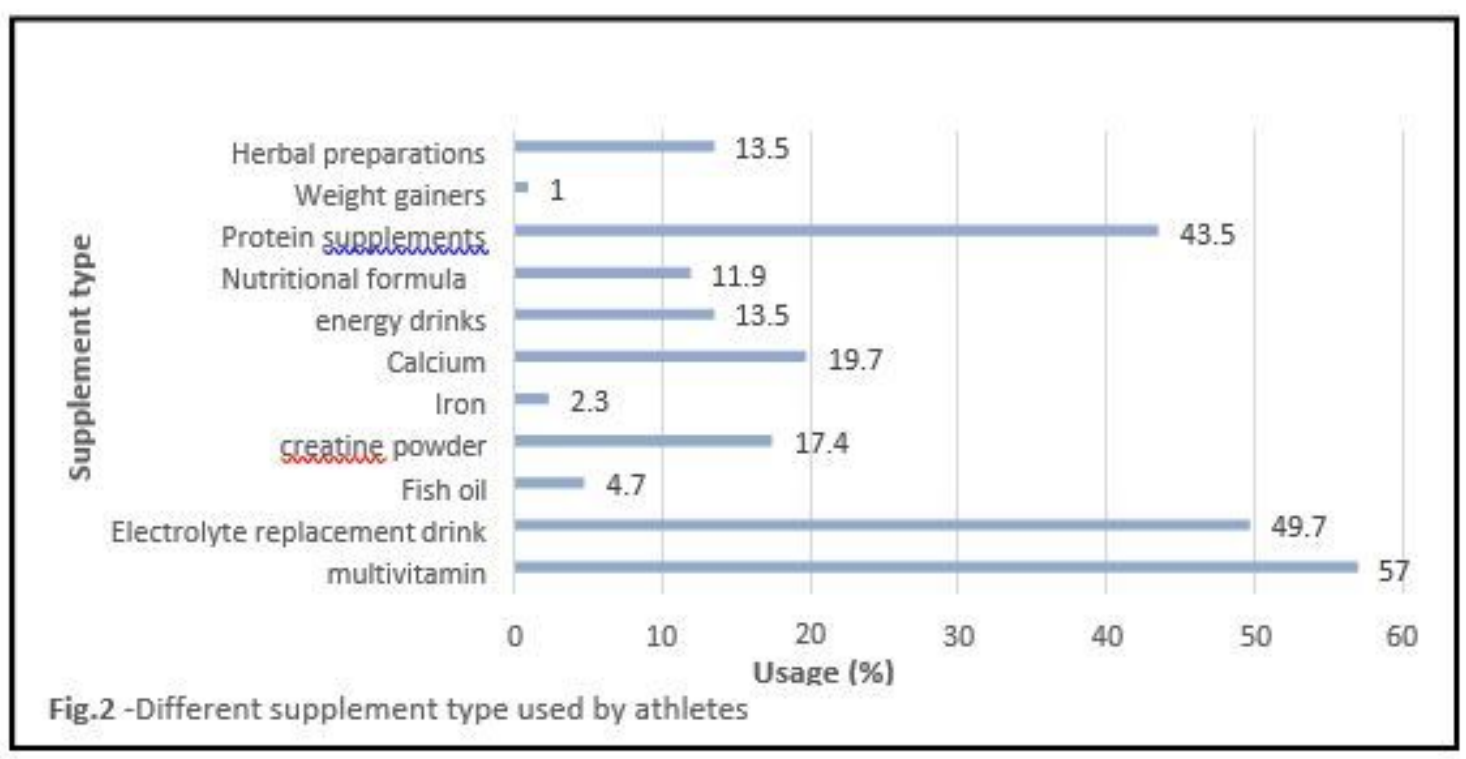

Figure 2 
Figure 2

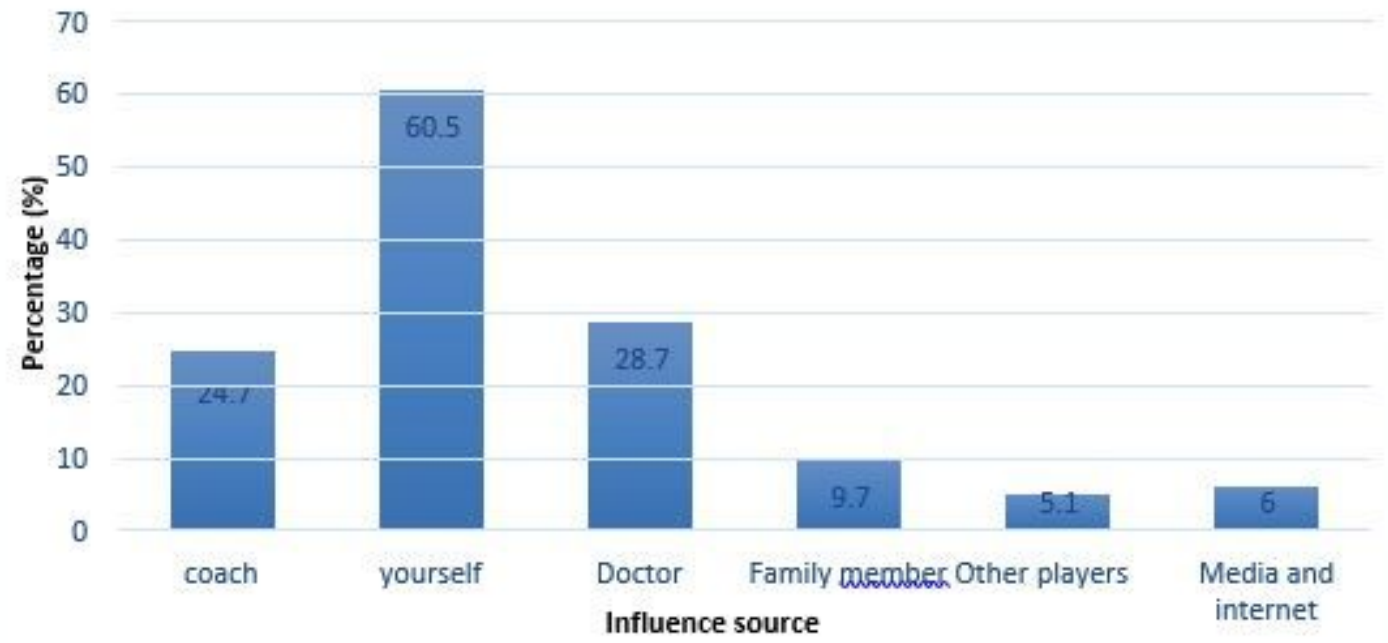

Fig.3-Distribution of influence sarces affected to supplement use

\section{Figure 3}

Figure 3

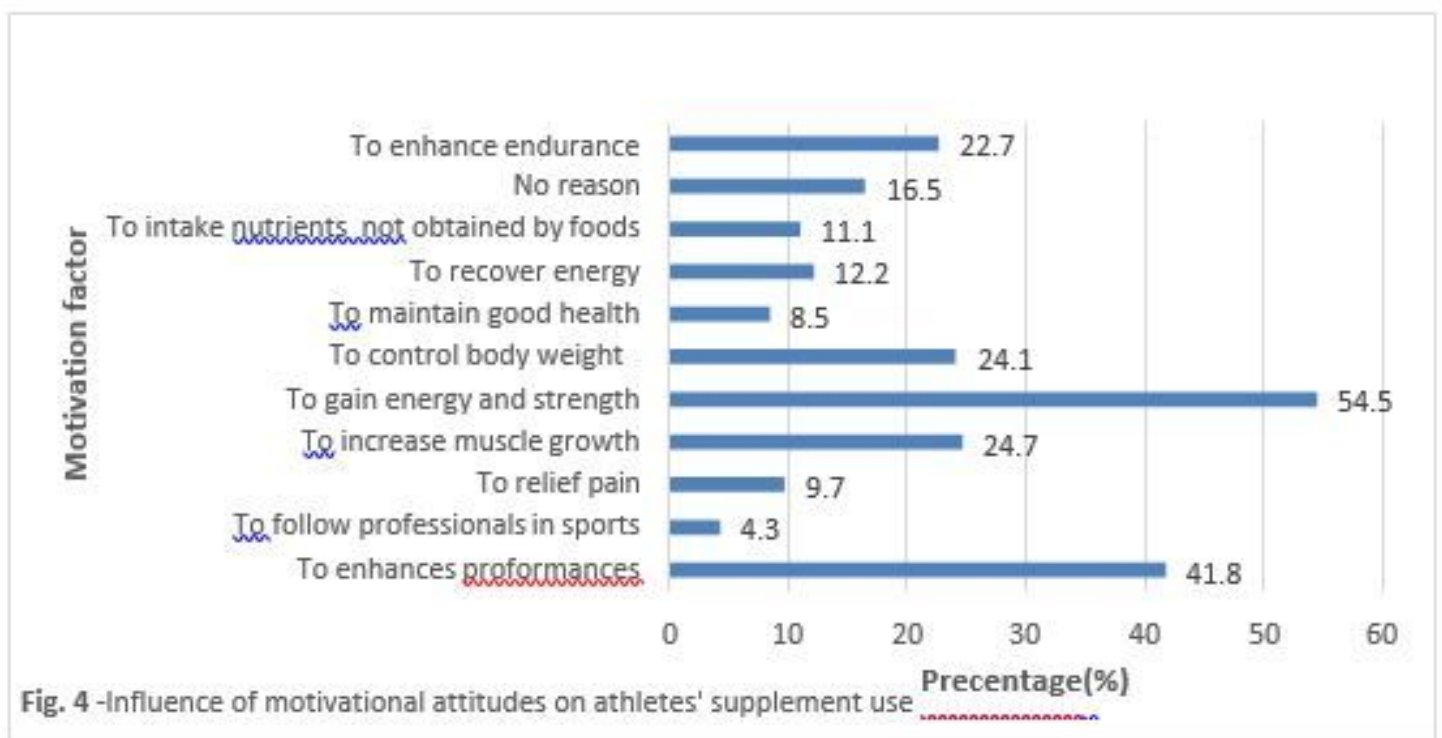

\section{Figure 4}

Figure 4 